\title{
Seamless Evaluation of Interactive Digital Storytelling Games: Edugames4All
}

\author{
Patty Kostkova \\ City eHealth Research Centre \\ City University London \\ pattyesoi.city.ac.uk
}

\begin{abstract}
Interactive Digital Storytelling (IDS) is a growing hybrid discipline bringing together computer games and cinematic storytelling enabling entertaining education. CeRC developed IDS game "Edugame4All" to improve children understanding of hygiene and responsible antibiotic use. This short paper presents an evaluation results assessing knowledge gain against the project prescribed learning objectives and proposes a novel framework called "seamless evaluation" inserting fine-grain questions into the story narrative and introducing a debrief session to evaluate without decreasing players' immersion.
\end{abstract}

Keywords: educational web games, game evaluation, interactive storytelling.

\section{Introduction}

Serious games are increasingly becoming established as a new method of education [1]. IDS is a growing hybrid discipline bringing together computer games and cinematic storytelling enabling a creation of unique learning applications [2]. The positive use of games to aid learning has been established [3-4]. The Edugames4All project (www.edugames4all.org) based on the DG SANCO-funded e-Bug project (www.ebug.eu) developed a story-telling game to teach children basic principles of hygiene and antibiotic resistance [5]. As a traditional 'role-playing game' it relies heavily on narrative [2]. There were 3 missions implemented, each teaching a set of learning objectives (LOs) prescrived by the project. In this paper we discuss the evaluation results and propose a seamless evaluation utilizing the storytelling nature of the game and engaging the player in a dialogue with the characters allowing to fine-tune the understanding of the player while not disturbing the immersion.

\section{Interactive Story Telling and Edugames4All}

Unlike linear digital storytelling, an interactive storytelling makes the player "feel" he/she is changing the course of the game. As defined by O'Hagan, the diagram in Figure 1 illustrates the 4 levels of the game.

\subsection{Edugames4All: Case Study}

The IDS mechanics was chosen based on focus groups conducted with 13-15 years old children in the UK [6]. There are three puzzles to solve, each testing several LOs.

P. Kostkova, M. Szomszor, and D. Fowler (Eds.): eHealth 2011, LNICST 91, pp. 80-84, 2012.

(C) Institute for Computer Sciences, Social Informatics and Telecommunications Engineering 2012 
Here we describe the first puzzle based around hand hygiene related LOs (the 2nd and $3^{\text {rd }}$ teach appropriate use of antibiotics and the issue of antibiotic resistance). Referring to standard IDS levels, defined in [1], illustrated on Figure 1, in the "animation base", the player is presented with a scene, chooses narrative to talk to characters, collects evidence, investigates evidence in a laboratory and presents an answer to "puzzle" the cause of infection or reason for an illness - to the boss of e- Bug ("Big C" character, Figure 2). At the second "dialog base", there is the story. For example, the story in the first puzzle is as follows: at a BBQ party, a famous actor gets by infection transmitted as a result of poor hand hygiene at a bathroom but poisoning food and insufficient hygiene in the kitchen must be eliminated by investigating a Chef and by collecting and testing evidence samples. Investigate dialogue in the kitchen scene is illustrated on Figure 3.

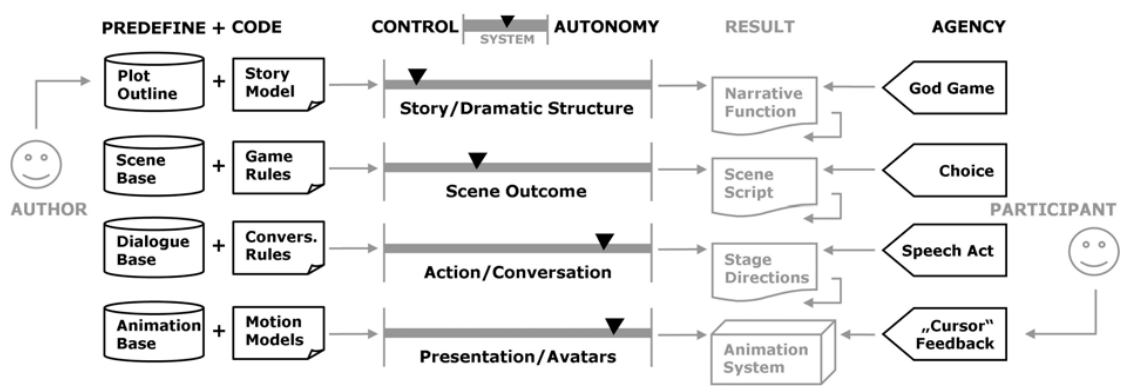

Fig. 1. 4 levels of interactive story-telling (taken from [1])

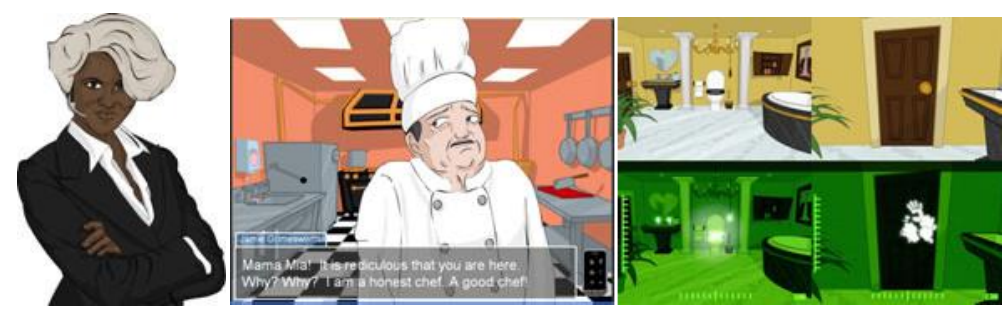

Fig. 2. Big C Fig. 3. Chef investigation narrative

Fig. 4. "Micro-vision"

The game mechanics "rules" require the player to test the samples and prove the hypothesis. This includes so called "micro-vision" (illustrated on Figure 4) turning the room into a "microbe-vision light" allowing users to see microbes on the scene and collect samples for testing in a microbiological laboratory. The evidence is tested and hypothesis about the cause of the infection either proved or disproved. Finally, on the 4th level - "plot outline" - the story "Big C at the Investigators HQ assigns player a task to investigate the reason of poisoning and approves the correct investigation outcome: the Actor's sickness was caused by a contamination of the salad at the BBQ by microbes transmitted due to poor hand hygiene at a toilet.

\section{Evaluation Results}

The games were evaluated during the development phase in schools in the UK in terms of knowledge change and usability. Final game was evaluated in summer 2010 
[Type here]

Table 1. Summary of player responses for questionnaires for each Mission, including the specific questions provided at each level corresponding to e-Bug pack learning outcomes. The pre and post responses are written via symbols between the ' $\&$ ' where $\mathrm{C}=$ correct, $\mathrm{W}=\mathrm{wrong}$, ?=other (either answer not provided or both True and False selected - wrong in either case). For example, ' $\mathrm{C} \& \mathrm{C}$ ' $=$ correct pre and correct post answers; ' $\mathrm{C} \&(\mathrm{~W} \mid$ ?) $=$ correct pre-answer and either wrong post-answer or other response selected. 'Remaining' refers to the tallied player responses for the following cases: '?\&?' , '?W', and 'W\&?'

\begin{tabular}{|c|c|c|c|c|c|c|c|c|c|c|}
\hline & & ssta & Finis & $\mathrm{csc}$ & $\mathrm{wew}$ & W:3:sc & (WW:2) & ining & rachises & allue \\
\hline \multirow{10}{*}{ Mission 1} & 1.V Virsuses and bacteria are two types of micro-organisms. & 22 & 10 & ${ }^{16}$ & 1 & 4 & 1 & 27 & 1.25 & 0.26 \\
\hline & 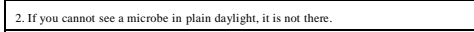 & 22 & 10 & ${ }_{18}$ & 0 & 3 & 1 & 27 & 0.56 & 0.45 \\
\hline & 3. Fungi are microbes. & 22 & 10 & ${ }^{17}$ & 2 & 3 & 0 & 27 & 2.08 & 0.15 \\
\hline & \begin{tabular}{|l|} 
4. Virus microbes can be spread by sneezing or coughing. \\
\end{tabular} & 22 & 10 & 18 & 0 & 2 & 2 & 27 & 0.06 & 0.80 \\
\hline & \begin{tabular}{|l} 
5. Virns microbes can be spread by sneezing or coughinge. \\
\end{tabular} & 22 & 10 & 19 & 0 & 0 & 3 & 27 & 4.08 & 0.04 \\
\hline & 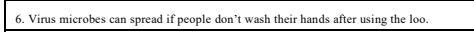 & 22 & 10 & ${ }^{20}$ & 0 & 1 & 1 & 27 & 0.13 & 0.72 \\
\hline & 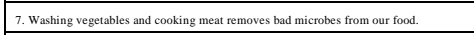 & 22 & 10 & ${ }^{19}$ & 1 & 1 & 1 & 27 & 0.13 & 0.72 \\
\hline & 8. People stould wash hier hands before eating. & 22 & 10 & 21 & $0_{0}$ & 0 & 1 & 27 & 2.25 & 0.13 \\
\hline & \begin{tabular}{|l|}
9 . Betorer making a meal, people don't neced to wash hair hands. \\
\end{tabular} & 22 & 10 & 20 & 1 & 0 & 1 & 27 & 2.25 & 0.13 \\
\hline & 10. Microbes are found on most surficess ilike your skin, or food that you eat. & 22 & ${ }_{10}$ & 19 & ${ }_{0}$ & 2 & 1 & 27 & 0.08 & 0.77 \\
\hline \multirow{10}{*}{ Mission 2} & 1. Anitioinics kill bacteria. & 14 & 10 & ${ }^{10}$ & 1 & 1 & 2 & 35 & 0.75 & 0.39 \\
\hline & 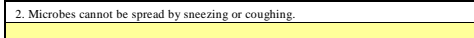 & 14 & 10 & 6 & 0 & 2 & 6 & 35 & 2.53 & 0.11 \\
\hline & 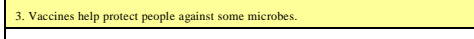 & 14 & 10 & 11 & 0 & 0 & 3 & 35 & 408 & 0.04 \\
\hline & 4. Bacteria and virsses are the same. & 14 & 10 & ${ }^{11}$ & 0 & 0 & 1 & 37 & 2.25 & 0.13 \\
\hline & 5. Antibioicis kill viruses. & 14 & 10 & ${ }^{3}$ & 4 & 5 & 1 & 36 & 2.04 & 0.15 \\
\hline & 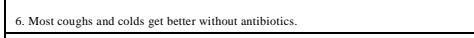 & 14 & 10 & 9 & 1 & 3 & 1 & 35 & 0.56 & 0.45 \\
\hline & 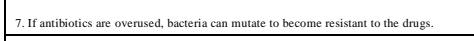 & 14 & 10 & 13 & 1 & 0 & 0 & 35 & N/A & $\mathrm{N} / \mathrm{A}$ \\
\hline & 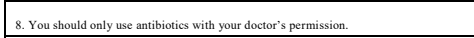 & 14 & 10 & 12 & 2 & 0 & 0 & 35 & N/A & 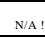 \\
\hline & 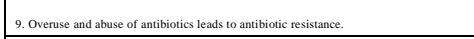 & 14 & 10 & 13 & 1 & 0 & 0 & 35 & $\mathrm{~N} / \mathrm{A}$ & $\mathrm{N} / \mathrm{A}$ \\
\hline & 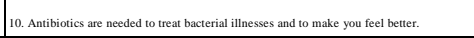 & 14 & 10 & 11 & 1 & 2 & . & 35 & 1.13 & 0.29 \\
\hline \multirow{10}{*}{ Mission 3} & \begin{tabular}{|l|l} 
1. Microbes are contagious. \\
\end{tabular} & 22 & 13 & 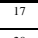 & 0 & 3 & 2 & 27 & 0.05 & 0.82 \\
\hline & 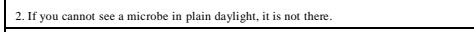 & 22 & 13 & 20 & 0 & 1 & 1 & 27 & 0.13 & 0.72 \\
\hline & 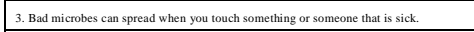 & 22 & 13 & 18 & 1 & 3 & 0 & 27 & 2.08 & 0.15 \\
\hline & \begin{tabular}{|l|l} 
4.If people wash hieir hands, they yre less iliely to get ill. \\
\end{tabular} & 22 & 13 & ${ }^{19}$ & 0 & 3 & 0 & 27 & 2.08 & 0.15 \\
\hline & \begin{tabular}{|l|} 
5. Yous should only yse antibioitis wiih your docotors perminsision. \\
\end{tabular} & 22 & 13 & ${ }^{19}$ & 0 & 0 & 3 & 27 & 4.08 & 0.04 \\
\hline & \begin{tabular}{|l}
6 . You can stop taking anitioiois when you are feceling better. \\
\end{tabular} & 22 & 13 & 7 & 5 & 7 & 3 & 27 & 1.23 & 0.27 \\
\hline & 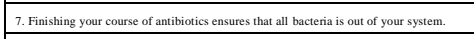 & 22 & 13 & 7 & 6 & 6 & 3 & 27 & 0.69 & 0.40 \\
\hline & 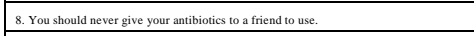 & 22 & 13 & 22 & $0_{0}$ & 0 & 0 & 27 & N/A & N/A \\
\hline & 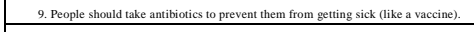 & 22 & 13 & 12 & 3 & 3 & 4 & 27 & 0.32 & 0.57 \\
\hline & 10. Anitibioics kil our good bacteriain our gut. & 22 & 13 & ${ }_{10}^{10}$ & $=$ & 7 & 3 & 27 & 1.23 & 0.27 \\
\hline
\end{tabular}


by 49 students attending "Technology Camp," a summer school held at Elstree School, near Reading, Berkshire. Their age range was 10-13 year olds including both girls and boys. The study took two 1.5 hour timeslots provided for each of the two sets of children (divided at the convenience of the summer school counselors). The results of the evaluation using pre and post questionnaire, administered on paper before and after children played the game, were analyzed using t-pair test and McNemar test, as illustrated in Table 1. We observed a large dropout rate (which is not unusual and was observed at the junior game evaluation [6]). Mission $1-22$ started, 10 finished Mission 2 - 14 started, 10 finished, Mission 3 - 22 started, 13 finished. Further Several students played more than one mission - hence the higher starting numbers for Missions 1 and 3. On average (49 students divided into thirds), approximately 16 students should have played each Mission. The prescribed Learning Outcomes were mapped to individual Missions as requested by the project, however, as they were the least common denominator across European science curricula these proved to be too simple and did not provide a sufficient level of granularity. Table 1 illustrates most kids at this science camp knew correct answers beforehand, thus, we could measure little significant knowledge change. A negative result was achieved - $\mathrm{P}=0.04$ for three LOs; however, the knowledge change was from correct to incorrect. The problem was that the majority of students knew the answers before game playing as the level of biology and science knowledge at the camp was well above average. Secondly, the LO set to allow unification of the project aims cross Europe proved too simple to test a deeper understanding but provided a baseline for a novel finer-grained seamless evalution.

\section{Work in Progress: Seamless Evaluation}

In addition to designing the LOs at the right level of depth to better evaluate the educational impact of games, the administration of tests needs to be "seamless" by inserting questions in the game mechanics in order to decrease an exposure suspicion bias while maintaining user immersion and enjoyment. The need for innovative nonintrusive approach to evaluation has been highlighted [8], however, to actually design a seamless evaluation framework an appropriate design methods matching the mechanics of evaluating game are required. In our previous research, a seamless evaluation of the Edugames4All platform game was achieved by inserting a "How to be a Millionaire" scenes (player was asked questions in a competitive quiz format) before and after playing a bacteria fighting session in human body [5]. IDS games are providing a nature format for seamless evaluation. Further, to enhance the leaving effect a "debriefing" phase is to be inserted providing reflections on one's decisions by observing the game from critical distance [3]. Alex, the "investigator" characters in Edugames4All, has to return to the Mission HQ and report each decision back to Big C. These two implementations of seamless evaluation are currently in tested on a Global Handwashing Day Game [7] and preliminary results will be presented at the conference. 


\section{Conclusion}

Computer games have been established as new media for education. We described the design of the IDS game Edugames4All teaching hygiene and antibiotic resistance and the results of an evaluation using pre and post questionnaires methodology. A work in progress method, the seamless evaluation, integrating fine-grained questions into the game dialogue and introducing a "debrief" session evaluates knowledge gain without decreasing players' immersion.

Acknowledgements. Thanks to DG SANCO, David Farrell, L Lazareck, D Weerasinghe, e-Bug team lead by C McNulty, J Weinberg, D Lecky; and artists N Lai, $S$ Beveridge.

\section{References}

[1] O'Hagan, M.: Video games as a new domain for translation research, Revista Tradumàtica - Traducció I Tecnologìes de la Informaciŏ I la Comunicaciŏ 05: Localitzaciŏ de videojocs, ISSN 1578-7559,

http://www.fti.uab.cal/tradumatica/revista

[2] Spieerling, U.: Interactive Digital Storytelling: Towards a Hybrid Conceptual Approach. In: Proceedings of DiGRA 2005 Conference: Changing Views - Worlds in Play (2005)

[3] Klabbers, J.: The gaming landscape: A taxonomy for classifying games and simulations. In: Copier, Raessens (eds.) Level up: Digital Games Research Conference, Utrecht Uni. (2003)

[4] Robertson, J., Collins, T., Kelly, A.: Tales of Adventure Author: Learning through Making Games. Narrative and Interactive Learning Environments, Edinburgh (2008)

[5] Farrell, D., Kostkova, P., Lazareck, L., Weerasinghe, D.: Developing web games to teach microbiology. The Journal of Antimicrobial Chemotherapy 66(suppl. 5), v33-v38

[6] Farrell, D., Kostkova, P., Weinberg, J., Lazareck, L., Weerasinghe, D., McNulty, C.A.M.: Computer games to teach hygiene: An evaluation of the e-Bug junior game. The Journal of Antimicrobial Chemotherapy 66(suppl. 5), v39-v44

[7] http://www.edugames4all.org/IntegratedCRD.nsf/a2e0dec55e90ea ac $80257914005 a d 890 /$ c7b7205052d61c578025791400661778? OpenDocu ment

[8] Vavoula, G., Meek, J., Sharples, M., Lonsdale, P., Rudman, P.: A Lifecycle Approach to Evaluating MyArtSpace. In: Proc. 4th Int. Workshop of WMUTE 2006, pp. 18-22 (2006) 